\title{
Escherichia coli-based production of recombinant ovine angiotensinogen and its characterization as a renin substrate
}

Shinji Yamashita ${ }^{1}$, Naoya Shibata², Akiyoshi Boku-lkeda ${ }^{3}$, Erika Abe ${ }^{2}$, Ayumi Inayama², Takashi Yamaguchi², Ayano Higuma ${ }^{4}$, Kaoru Inagaki ${ }^{2}$, Tomoyo Tsuyuzaki ${ }^{4}$, Satoshi Iwamoto ${ }^{4}$, Satoshi Ohno ${ }^{3}$, Takashi Yokogawa ${ }^{3}$, Kazuya Nishikawa ${ }^{3}$, Kazal Boron Biswas ${ }^{4}$, A. H. M. Nurun Nabi ${ }^{5}$, Tsutomu Nakagawa ${ }^{4}$, Fumiaki Suzuki ${ }^{4}$ and Akio Ebihara ${ }^{4^{*}}$

\begin{abstract}
Background: Angiotensinogen (ANG) is a macromolecular precursor of angiotensin, which regulates blood pressure and electrolyte balance. ANG is specifically cleaved by renin, an aspartic protease, to initiate the angiotensin-processing cascade. Ovine ANG (OANG) from sheep plasma has been shown to be a better substrate for human renin, and it has been used in clinical renin assays. To expand the availability of OANG, we aimed to produce milligram levels of recombinant oANG using an Escherichia coli expression system.

Results: When recombinant OANG was expressed from a T7 promoter in various E. coli strains at $37^{\circ} \mathrm{C}$, it accumulated in the insoluble fraction. However, by expressing $\mathrm{OANG}$ at $37^{\circ} \mathrm{C}$ from a tac promoter, which has weaker transcriptional activity than a T7 promoter, we significantly elevated the ratio of soluble to insoluble recombinant oANG. Using a novel culturing system and auto-induction culture medium, we purified tac-expressed recombinant oANG to homogeneity, with a yield of $4.0 \mathrm{mg}$ per liter of culture. Based on size-exclusion gel filtration analysis and dynamic light scattering analysis, the resulting purified $O A N G$ is a monomer in solution. The circular dichroism spectrum of $E$. coli-expressed recombinant OANG was similar to that of oANG expressed in $\mathrm{CHO}$ cells. Differential scanning fluorimetry showed that both preparations undergo a two-state transition during thermal denaturation, and the melting temperatures of recombinant oANG expressed in $\mathrm{E}$. coli and $\mathrm{CHO}$ cells were $49.4 \pm 0.16^{\circ} \mathrm{C}$ and $51.6 \pm 0.19^{\circ} \mathrm{C}$, respectively. The $K_{m}$ values of both oANG preparations were similar; the $k_{\text {cat }}$ value of $E$. coli-expressed recombinant oANG was slightly higher than that of CHO-expressed oANG.

Conclusions: Recombinant oANG expressed in E. coli functions as a human renin substrate. This study presents an $E$. coli-based system for the rapid production of milligram quantities of a human renin substrate, which will be useful for both fundamental and clinical studies on renin and hypertension.
\end{abstract}

Keywords: Angiotensinogen, Renin, Angiotensin, Hypertension, Plasma renin concentration, E. coli, Recombinant protein production, Auto-induction

\footnotetext{
* Correspondence: aebihara@gifu-u.ac.jp

${ }^{4}$ Faculty of Applied Biological Sciences, Gifu University, 1-1 Yanagido, Gifu

501-1193, Japan

Full list of author information is available at the end of the article
} 


\section{Background}

Angiotensinogen (ANG) is a 452-amino acid plasma glycoprotein. This protein is specifically cleaved by the aspartic protease renin (EC 3.4.23.15) to release the $\mathrm{N}$-terminal decapeptide angiotensin I (AI). AI is further hydrolyzed by angiotensin-converting enzyme (EC 3.4.15.1) to produce the octapeptide angiotensin II, which regulates blood pressure and electrolyte balance [1]. ANG-deficient mice [2] and renin-deficient mice [3] exhibit profound hypotension, and no detectable AI was found in the plasma of mice with either knockout mutation $[2,3]$. These in vivo studies demonstrate the biological importance of enzymatic cleavage of ANG by renin.

Human renin has a much higher affinity for and shows a much greater velocity with ovine ANG (oANG) than human ANG [4-6]. Native oANG, purified from sheep plasma, has been shown to be a better substrate for human renin, and it has been used in clinical renin assays [6]. The purification process for native oANG has been established $[4,7]$ : one study reported obtaining approximately $35 \mathrm{mg}$ of native oANG from $1 \mathrm{~L}$ of plasma from a nephrectomized sheep [7]. As an alternative to native oANG, we prepared recombinant oANG using a Chinese hamster ovary $(\mathrm{CHO})$ cell line that permanently expresses this protein [8], with a yield of approximately $8 \mathrm{mg}$ purified oANG per liter of culture medium. Although sheep and a $\mathrm{CHO}$ cell line are effective sources for preparing milligram quantities of oANG, an animal and cell culture equipment, respectively, are required to produce oANG. Moreover, about one month of cell culture is required to obtain such amounts of recombinant oANG. Biotechnological advances that make it possible to prepare a large amount of oANG should facilitate clinical studies on renin.

To increase the availability of oANG, we aimed to produce recombinant oANG using an Escherichia coli expression system, which makes it possible to express the protein in a few days. Here, we report an E. coli-based system for the production of milligram levels of recombinant oANG and show that recombinant oANG expressed in $E$. coli functions as a human renin substrate.

\section{Results}

\section{Expression screening of recombinant oANG in E. coli}

As a first step towards expressing recombinant oANG in E. coli, we compared the effects of different host strains, induction levels, expression temperatures, and promoters on the solubility of oANG. Recombinant oANG was first expressed from an isopropyl-beta-D-thiogalactoside (IPTG)-inducible $\mathrm{T} 7$ promoter at $37^{\circ} \mathrm{C}$ in DE3 lysogens of six tested E. coli strains. Under these conditions, oANG was found in the insoluble fraction of the cell lysate (Fig. 1a and c). We also found that E. coli B strains produced more oANG than E. coli $\mathrm{K}$ strains (Fig. 1a and c). When we reduced the expression temperature to $25{ }^{\circ} \mathrm{C}$, no significant band corresponding to oANG was detected on a CBB stained SDS-polyacrylamide gel (Fig. 1b). Western blotting showed that when expressed at $25{ }^{\circ} \mathrm{C}$, a small portion of the total oANG was located in the soluble fraction of the BL21(DE3), Rosetta 2(DE3), Tuner(DE3), and SHuffle T7 Express Competent (SHB) E. coli cell lysates (Fig. 1d). These results suggest that reducing the expression temperature facilitated proper folding, which yielded a higher amount of soluble oANG.

The tac promoter is a hybrid of the lac and trp promoters, and its transcriptional activity is weaker than that of the T7 promoter [9]. To produce soluble oANG at high yield, we expressed His-tagged oANG from an IPTG-inducible tac promoter at $37{ }^{\circ} \mathrm{C}$ in E. coli BL21 cells. To examine the amount of soluble oANG, we purified it from the supernatant of the cell lysate using $\mathrm{Ni}$ affinity chromatography. The bound fraction contained a protein band with an estimated molecular weight that is similar to that of oANG (Additional file 1). This protein was identified as oANG by peptide mass fingerprinting using matrix-assisted laser desorption/ionization timeof-flight mass spectrometry. Next, we compared the effect of promoters on the solubility of recombinant oANG. When expressed from a T7 promoter, oANG accumulated in the insoluble fraction, and only a small proportion of oANG was located in the soluble fraction (Fig. 2a). In contrast, the soluble to insoluble ratio was approximately 1:1 when oANG was expressed from the tac promoter (Fig. 2a). These results indicate that expression from a weaker promoter (i.e., the tac promoter) increased the ratio of soluble to insoluble recombinant oANG.

\section{Purification of recombinant oANG expressed in E. coli}

To prepare a larger amount of oANG, we harvested cell pellets (wet weight: $45 \mathrm{~g}$ ) from a $15-\mathrm{L}$ batch culture of $E$. coli BL21 cells harboring pTAC-oANG-His. After three successive chromatography steps, including a Ni-affinity column, an ion-exchange column, and a gel filtration column, approximately $0.27 \mathrm{mg}$ of purified His-tagged oANG was obtained per liter of culture. When reacted with human renin, this preparation produced AI, indicating that the purified oANG is a functional renin substrate.

To increase the yield of soluble, active oANG, we utilized both auto-induction culture medium and a novel culture system to express His-tag-fused oANG from a $t a c$ promoter at $30{ }^{\circ} \mathrm{C}$ in E. coli BL21 cells. The absorbance of the culture medium at $600 \mathrm{~nm}\left(\mathrm{OD}_{600}\right)$ was approximately 15 , indicating the high efficiency of this culture system. Using the three chromatographic steps described above, oANG was purified to homogeneity according to SDSPAGE (Fig. 2b). Its molecular weight was estimated to be $50 \mathrm{k}$, which is similar to its calculated molecular mass (50.3 kDa). 

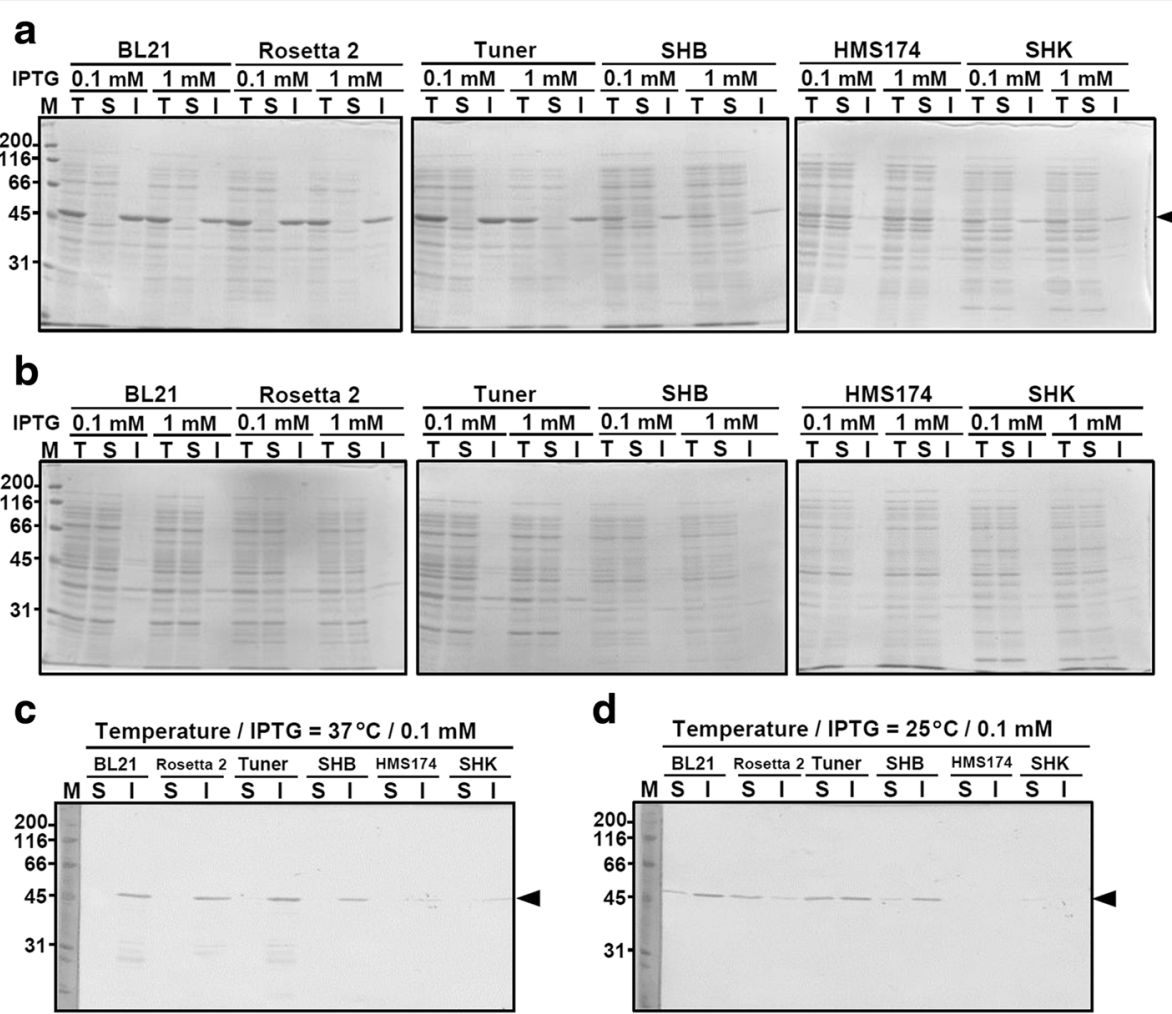

Fig. 1 Expression screening of recombinant oANG in E. coli. Comparison of oANG expression and solubility using different E. coli (DE3) host strains and IPTG concentrations at $37^{\circ} \mathrm{C}(\mathbf{a})$ and $25^{\circ} \mathrm{C}(\mathbf{b})$. Recombinant oANG was expressed from pET-11a-oANG in E. coli (DE3) lysogens following induction with IPTG (0.1 and $1.0 \mathrm{mM}$ ), separated by SDS-polyacrylamide gel electrophoresis (SDS-PAGE), and then stained with Coomassie Brilliant Blue (CBB). Lane M, molecular marker; lane T, total cell lysate; lane S, soluble fraction; lane I, insoluble fraction. Western blot analysis of oANG expressed at $37^{\circ} \mathrm{C}(\mathbf{c})$ and $25^{\circ} \mathrm{C}$ (d) induced with IPTG (0.1 mM). Soluble (S) and insoluble (I) fractions of the cell lysates were analyzed by western blotting with an anti-oANG polyclonal antibody. Molecular markers (M) were visualized by CBB staining. The molecular weights of the marker proteins are shown on the left. The arrowhead on the right shows the size of oANG

The specific amount in the final preparation was $23.5 \mu \mathrm{g}$ of $\mathrm{AI} / \mathrm{mg}$ of total protein. Assuming a molecular mass of $50.3 \mathrm{kDa}$ for oANG and that one mole of oANG yields one mole of AI with a molecular mass of $1.296 \mathrm{kDa}$, the theoretical specific amount of ANG is $25.8 \mu \mathrm{g}$ of $\mathrm{AI} / \mathrm{mg}$. Based on this value, the purity of the final preparation was $91 \%$. The production yield was approximately $4.0 \mathrm{mg}$ of purified oANG per liter of culture, although $0.5 \mathrm{~L}$ of culture (cell pellet wet weight: $8.7 \mathrm{~g}$ ) was routinely used for oANG production. On the other hand, the production yield using $\mathrm{CHO}$ cells was approximately $2.3 \mathrm{mg}$ of purified oANG per liter of culture. In the following analyses, recombinant oANG expressed in E. coli (oANG $\mathrm{Ecoli}_{\text {) }}$ ) was compared with that expressed in $\mathrm{CHO}$ cells $\left(\mathrm{oANG}_{\mathrm{CHO}}\right)$.

\section{Protein size analysis of recombinant oANG}

To examine the molecular size of recombinant oANG, we used analytical size-exclusion gel filtration and dynamic light scattering (DLS). The results of size-exclusion gel filtration showed that both recombinant oANG $\mathrm{Ecoli}_{\mathrm{i}}$ and $\mathrm{oANG}_{\mathrm{CHO}}$ exhibited one major peak (Fig. 3a). The apparent molecular weight of recombinant oANG $\mathrm{Ecoli}_{\mathrm{i}}$ was $42 \mathrm{k}$. In contrast, recombinant oANG $\mathrm{CHO}_{\mathrm{CH}}$ eluted more quickly (Fig. 3a), and its apparent molecular weight was $56 \mathrm{k}$. The DLS results (Fig. $3 \mathrm{~b}$ ) showed that recombinant $\mathrm{oANG} \mathrm{Ecoli}_{\text {and }}$ aANG $\mathrm{AHO}_{\mathrm{CHO}}$ displayed one size distribution, with 19.1 and $26.5 \%$ polydispersity, respectively. The hydrodynamic radii of recombinant $\mathrm{oANG}_{\mathrm{Ecoli}}$ and $\mathrm{oANG}_{\mathrm{CHO}}$ were estimated to be $3.05 \pm$ $0.58 \mathrm{~nm}$ and $3.02 \pm 0.80 \mathrm{~nm}$, respectively, corresponding to globular proteins with molecular masses of $45.7 \mathrm{kDa}$ and $44.8 \mathrm{kDa}$, respectively. As the calculated molecular mass is $50.3 \mathrm{kDa}$ (see Methods), these results show that recombinant oANG is a monomer in solution. This finding is consistent with our previous report on $\mathrm{oANG}_{\mathrm{CHO}}[10]$.

\section{Protein structure and stability analysis of recombinant oANG}

Circular dichroism (CD) analysis was carried out to obtain secondary structural information for recombinant oANG. The CD spectrum of recombinant oANG $\mathrm{Ecoli}_{\text {was }}$ similar to that of oANG ${ }_{\mathrm{CHO}}$ (Fig. 4a). Recombinant oANG Ecoli was estimated to be composed of $24 \%$ alpha helix and 


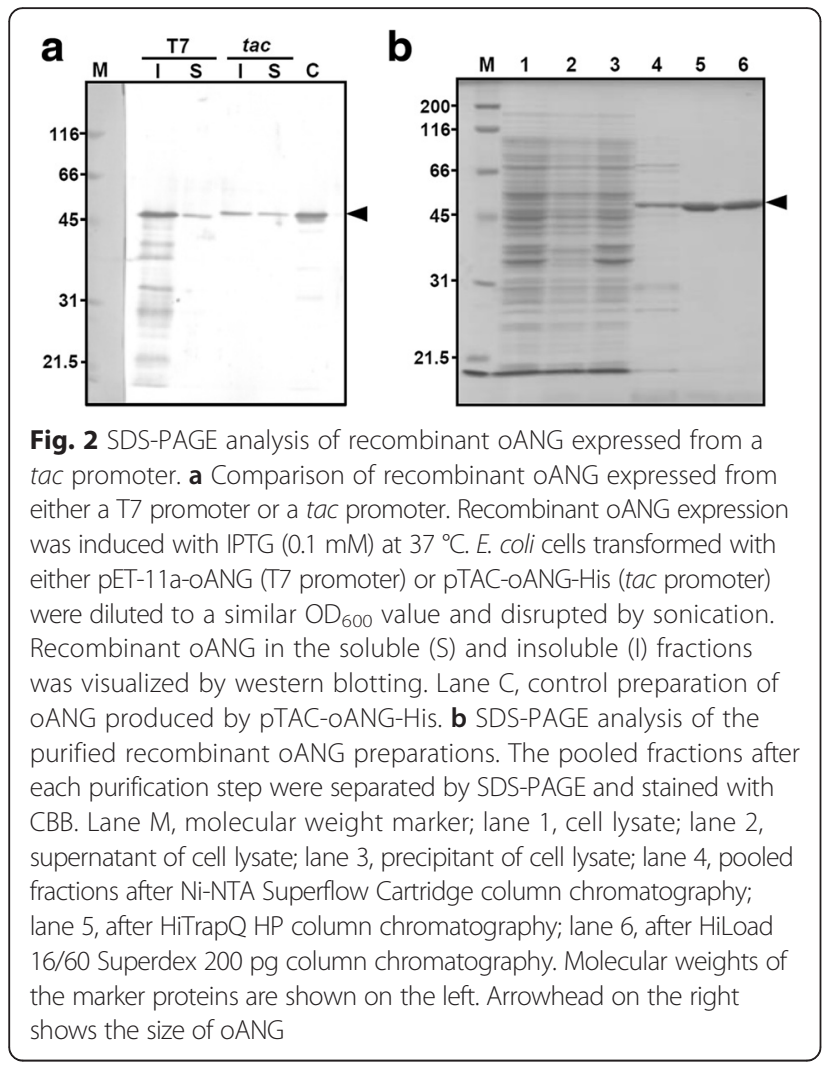

$22 \%$ beta strand. These values are similar to those calculated from the crystal structure of human angiotensinogen [PDB ID: 2WXW], which is composed of $28 \%$ alpha helix and $23 \%$ beta strand.

To examine the stability of recombinant oANG, we used differential scanning fluorimetry (DSF). This method monitors the thermal unfolding of proteins in the presence of a hydrophobic fluorescent dye, and then the fluorescence intensity is plotted as a function of temperature [11]. The resulting intensity plot is used to estimate the melting temperature $\left(T_{\mathrm{m}}\right)$. The DSF results (Fig. $4 \mathrm{~b}$ ) showed that both recombinant oANG products $(\mathrm{CHO}$ and E. coli) undergo a two-state transition during the course of thermal denaturation. The $T_{\mathrm{m}}$ of recombinant $\mathrm{oANG}_{\text {Ecoli }}$ and oANG $\mathrm{CHO}_{\mathrm{C}}$ was $49.4 \pm 0.16{ }^{\circ} \mathrm{C}$ and $51.6 \pm$ $0.19{ }^{\circ} \mathrm{C}$, respectively (Fig. $4 \mathrm{c}$ ).

\section{Human renin reactivity}

To determine whether the catalytic efficiency of recombinant oANG $\mathrm{Ecoli}_{\text {is }}$ comparable to oANG $\mathrm{CHO}_{\mathrm{CHO}}$, we carried out a steady-state kinetic analysis using both oANG preparations. Both exhibited a typical substrate saturation curve (Fig. 5). The Michaelis constant $\left(K_{\mathrm{m}}\right)$ values of the two preparations were similar, whereas the catalytic turnover $\left(k_{\text {cat }}\right)$ of oANG $\mathrm{Ecoli}_{\text {was }}$ wlightly higher than that of oANG $_{\mathrm{CHO}}$ (Table 1). The order of magnitude of the catalytic efficiency $\left(k_{\text {cat }} / K_{\mathrm{m}}\right)$ for the two preparations is

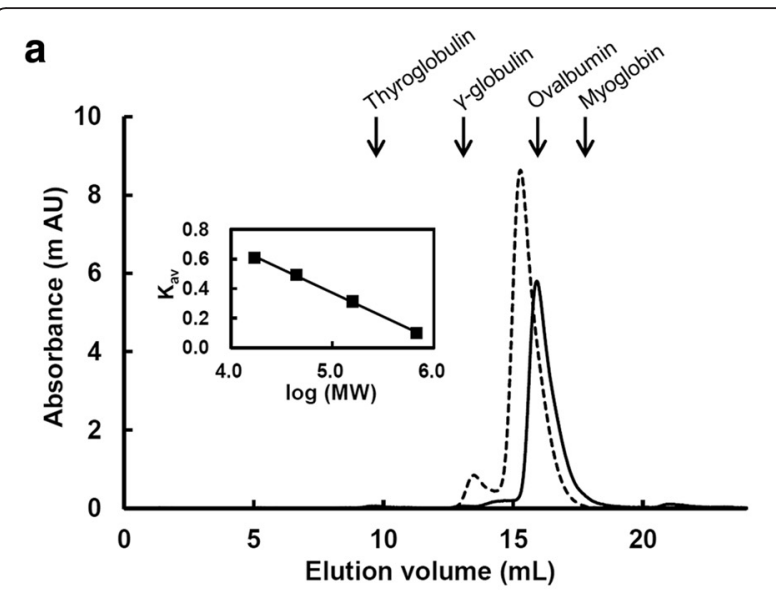

b

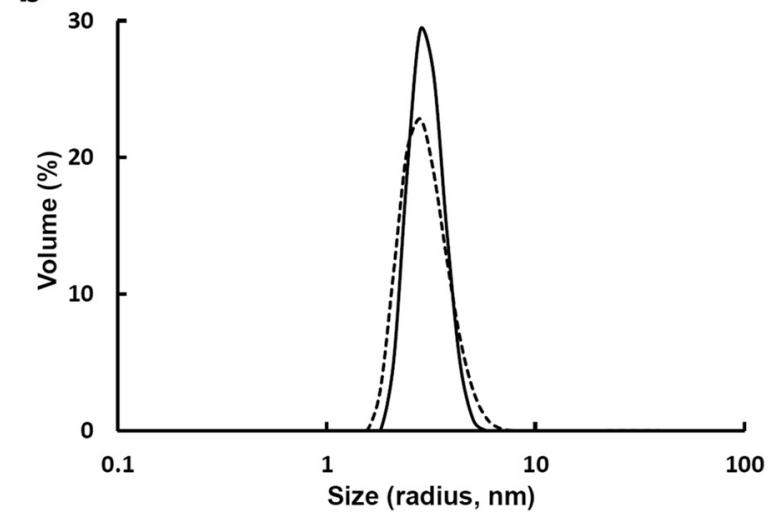

Fig. 3 Protein size analysis of recombinant OANG Ecoli and OANG $\mathrm{CHO}_{\mathrm{H}}$. The sizes of oANG Ecoli (solid line) and OANG $\mathrm{CHO}_{\mathrm{CH}}$ (dotted line) were determined by analytical size-exclusion gel filtration (a) and DLS (b). Purified oANG was loaded onto a Superdex 200 10/300 GL column equilibrated with $2 \mathrm{mM}$ HEPES and $0.20 \mathrm{M} \mathrm{KCl}(\mathrm{pH}$ 8.0). The elution volumes of the marker proteins are shown. The calibration curve is shown in the inset. DLS data were measured at $25^{\circ} \mathrm{C}$ in a pH 7.4 buffer solution containing $0.5 \mathrm{mg} / \mathrm{mL}$ oANG, $20 \mathrm{mM}$ sodium phosphate, and $20 \mathrm{mM}$ (OANG $\left.\mathrm{Ecol}_{i}\right)$ or $33 \mathrm{mM}$ (OANG $\mathrm{CHO}_{\mathrm{O}}$ ) KCl. The size distribution by percent volume is presented

in good agreement with that of a previous study by Nakagawa et al. [12].

\section{Discussion}

ANG has significant sequence homology to representative members of the serine protease inhibitor (serpin) superfamily [13]. Various recombinant serpins have been produced in E. coli [14]. When expressed in E. coli, some serpins are soluble, while others become insoluble and require refolding [14]. Kunapuli et al. [15] purified human ANG expressed from an IPTG-inducible lac promoter in E. coli. This preparation was cleaved by human kidney renin, as assessed by SDS-PAGE and western blotting; however, its enzymatic characterization was not reported [15]. Zou et al. [16] expressed recombinant human, mouse, and rat ANGs in E. coli using a SUMO-fusion 


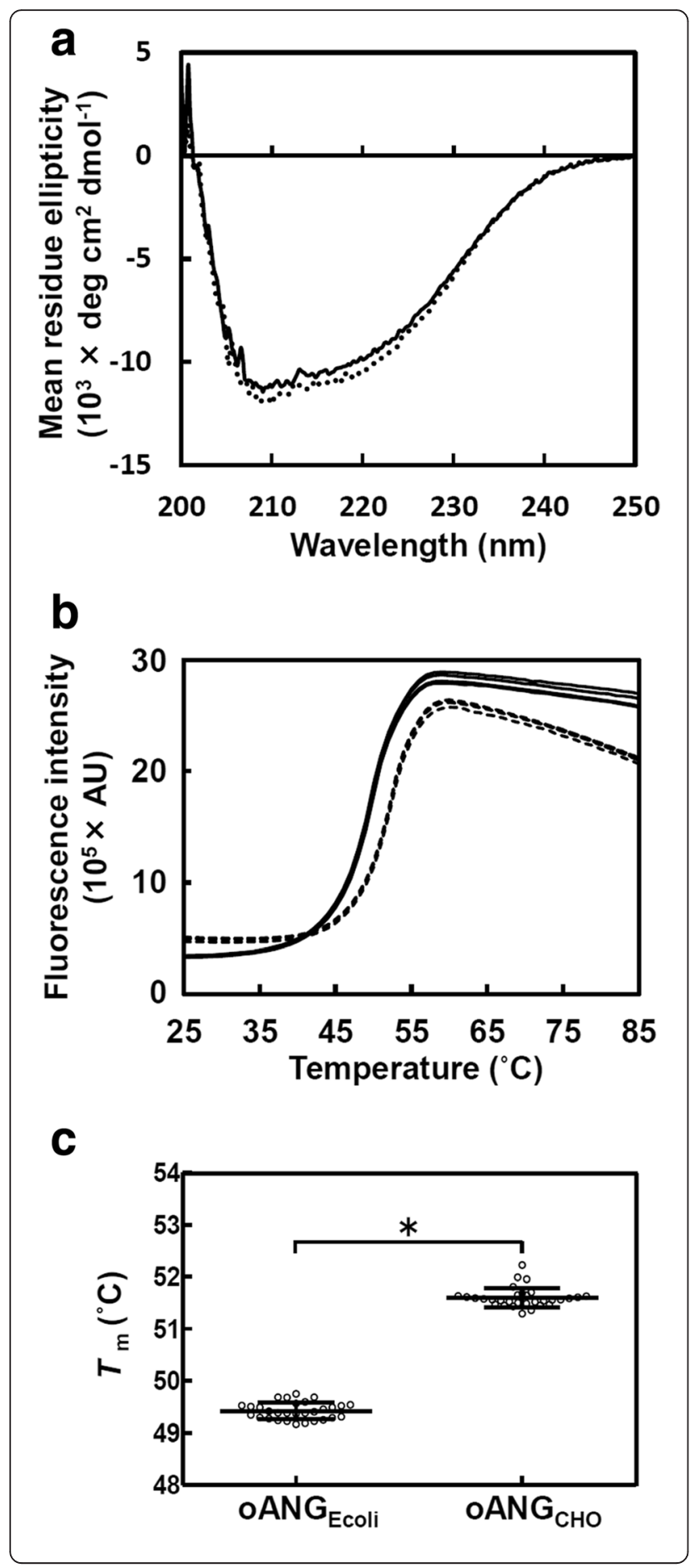

Fig. 4 Protein structure and stability analysis of recombinant OANG Ecoli and $\mathrm{OANG}_{\mathrm{CHO}}$. Purified $\mathrm{OANG}$ Ecoli (solid line) and $\mathrm{OANG}_{\mathrm{CHO}}$ (dotted line) were analyzed by $C D(\mathbf{a})$ and DSF $(\mathbf{b}) . \mathrm{CD}$ data were measured at $25^{\circ} \mathrm{C}$ in a pH 7.4 buffer solution containing $0.5 \mathrm{mg} / \mathrm{mL}$ oANG, $20 \mathrm{mM}$ sodium phosphate, and $20 \mathrm{mM}$ (OANG $\mathrm{ECOli}_{\text {) }}$ or $33 \mathrm{mM}$ (OANG $\mathrm{CHO}_{\mathrm{C}}$ ) KCl. DSF data were measured with $10 \mu \mathrm{M}$ oANG in $5 \times$ SYPRO Orange, $200 \mathrm{mM} \mathrm{HEPES}$, and $0.15 \mathrm{M} \mathrm{KCl}$ (pH 7.5). Five typical plots for each preparation are shown. c Comparison of the $T_{m}$ of oANG Ecoli and oANG $\mathrm{CHO}_{\mathrm{O}} T_{\mathrm{m}}$ values are plotted as open circles. The horizontal line and error bars are the mean value and standard deviation of the $T_{m}$ values, respectively (oANG Ecoli, $N=30 ; \mathrm{OANG}_{\mathrm{CHO}}, N=31$ ). ${ }^{*} P<0.0001$ by Student's t-test

system. According to the data deposited in the Protein Data Bank [PDB ID: 2WXW], a pSUMO3 plasmid with a T7 promoter was used to express human ANG. The authors characterized the enzymatic properties of human ANG and successfully determined the crystal structures of human, mouse, and rat ANG as well as a renin-ANG complex [16]. This report shows that the combination of E. coli and the SUMO-fusion system is a good choice for expressing recombinant ANG; however, the details of the expression and purification conditions are not available [16]. In the present study, a procedure was developed to prepare milligram quantities of recombinant oANG expressed in E. coli.

When recombinant oANG was expressed from a T7 promoter at $37{ }^{\circ} \mathrm{C}$ in various E. coli strains, it accumulated in the insoluble fraction (Fig. 1a and c). The breakthroughs in this study were $(a)$ the use of a $t a c$ promoter and $(b)$ the combination of a novel culture

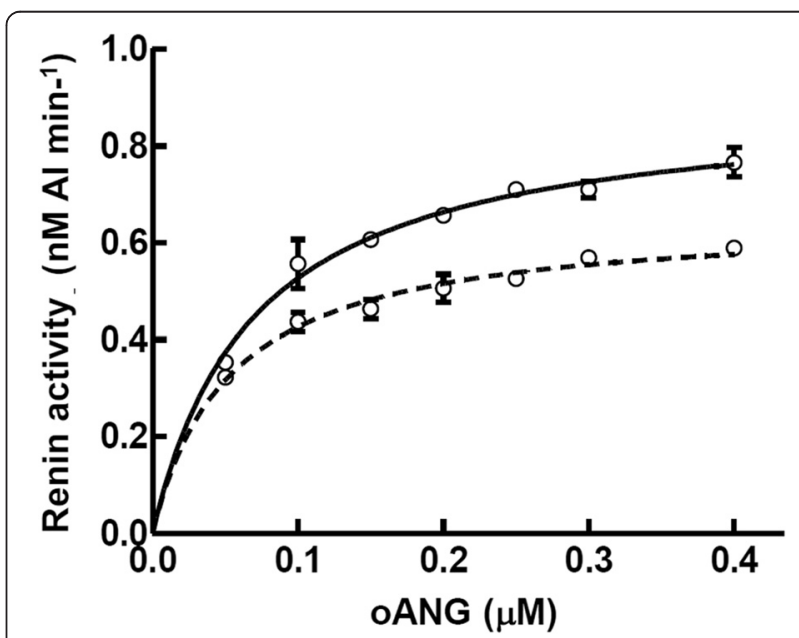

Fig. 5 Kinetic analysis of human renin with recombinant $O A N G_{E c o l i}$ and $\mathrm{OANG}_{\mathrm{CHO}}$. Renin activity in the presence of OANG Ecoli (solid line) and $\mathrm{OANG}_{\mathrm{CHO}}$ (dotted line) was analyzed by steady-state enzyme kinetics. Various concentrations of oANG were incubated with human renin ( $25 \mathrm{pM})$ at $37^{\circ} \mathrm{C}$ in sodium phosphate buffer ( $\mathrm{pH}$ 7.2) containing DFP and EDTA. The amount of Al produced was measured by enzyme-linked immunosorbent assay (ELISA). The error bars represent the standard deviation of the velocities $(N=3)$ 
Table 1 Kinetic parameters of recombinant $O A N G_{E c o l i}$ and $\mathrm{OANG}_{\mathrm{CHO}}$

\begin{tabular}{lccl}
\hline oANG & $k_{\mathrm{m}}(\mu \mathrm{M})$ & $k_{\text {cat }}\left(\mathrm{s}^{-1}\right)$ & $k_{\text {cat }} / K_{m}\left(\mathrm{M}^{-1} \mathrm{~s}^{-1}\right)$ \\
\hline oANG $_{\text {Ecoli }}^{\mathrm{a}}$ & 0.071 & 0.59 & $8.3 \times 10^{6}$ \\
oANG CHO $_{\text {CHO }}^{\mathrm{a}}$ & 0.072 & 0.46 & $6.4 \times 10^{6}$ \\
oANG $_{\text {CHO }}^{\mathrm{b}}$ & 0.090 & 0.31 & $3.4 \times 10^{6}$
\end{tabular}

${ }^{\mathrm{a}}$ This work

${ }^{\text {b}}$ Nakagawa et al. [12]

system and auto-induction culture medium. The former and the latter were shown to be useful in previous reports by Ikeda-Boku et al. [17] and Li et al. [18], respectively. When the protein was expressed from a tac promoter at $37^{\circ} \mathrm{C}$, the ratio of soluble to insoluble recombinant oANG increased significantly (Fig. 2a), and $4.0 \mathrm{mg}$ of recombinant oANG was prepared from a 15-L culture of E. coli. Although a milligram amount of oANG was obtained using this procedure, the production yield was relatively low (0.27 mg of oANG per liter of culture). With an aim to develop a higher-yield method, we devised a novel culture system in which $E$. coli cells were grown in culture medium that was aerated and agitated in a glass bottle. In addition, we used auto-induction medium [19] in which $E$. coli cells initiate recombinant protein expression from a lac-based promoter when they switch carbon sources from glucose to lactose. As a result, the production yield increased by a factor of 15 , from $0.27 \mathrm{mg}$ to $4.0 \mathrm{mg}$ of oANG per liter of culture. These breakthroughs enabled us to prepare a milligram quantity of oANG on a small culture scale.

We compared the biophysical and enzymatic properties of recombinant oANG $\mathrm{Ecoli}_{\text {and }}$ aANG $\mathrm{CHO}$. The proteins in both oANG preparations are a similar size (as estimated by DLS; Fig. 3b) and have similar secondary structural elements (Fig. 4a), a two-state transition during thermal denaturation (Fig. 4b), a similar affinity for human renin $\left(K_{\mathrm{m}}\right.$ value, Table 1$)$, and a similar catalytic efficiency $\left(k_{\mathrm{cat}} /\right.$ $K_{\mathrm{m}}$, Table 1$)$. These results strongly suggest that the threedimensional structure of recombinant $\mathrm{oANG}_{\mathrm{Ecoli}}$ is very similar to that of oANG $\mathrm{CHO}_{\mathrm{HO}}$. Although the transcription, translation, and post-translational modifications of proteins differ between $E$. coli and $\mathrm{CHO}$ cells, recombinant

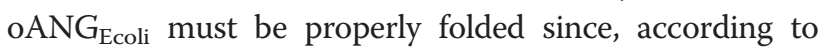
Anfinsen's dogma [20], the amino acid sequence of a protein is sufficient to determine its three-dimensional fold. In summary, these results show that recombinant oANG expressed in $E$. coli is functionally comparable to oANG expressed in $\mathrm{CHO}$ cells.

Recombinant oANG ${ }_{\mathrm{CHO}}$ possesses a single $N$-linked oligosaccharide chain [10]. On the other hand, recom-

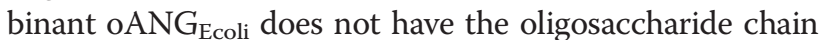
because standard $E$. coli cells do not attach oligosaccharide chains to $N$-linked glycosylation sites [21]. The absence of the $N$-linked oligosaccharide on oANG $\mathrm{Ecoli}_{\text {may }}$ be the cause of its lower $T_{\mathrm{m}}$ value (Fig. 4c).

Compared in terms of "production yield divided by expression days," the E. coli-based and CHO-based production systems produced 2.0 and $0.077 \mathrm{mg}$ oANG/liter of culture/day of culture, respectively. Therefore, the $E$. coli-based production system developed in this study is 26 times more time efficient than the $\mathrm{CHO}$-based system.

\section{Conclusions}

We developed an E. coli expression system that enables the rapid and easy production of recombinant oANG protein and successfully prepared $4.0 \mathrm{mg}$ of purified oANG per liter of culture medium. Recombinant oANG expressed in E. coli functions as a human renin substrate. Plasma renin concentration (PRC) is used as a clinical parameter related to hypertension [6]. This newly developed E. coli expression system makes human renin substrate more available, which will be useful for clinical studies on renin.

\section{Methods \\ Construction of expression plasmid}

The $o A N G$ gene was amplified by polymerase chain reaction (PCR) from a pcDNA3 mammalian expression vector harboring oANG cDNA [8]. The sequences of the forward and reverse primers were $5^{\prime}$-ATATATATcatatg GACCGCGTATACATCCACCCCTTCCACCTC-3'

(NdeI site in lower case) and 5'-ATTTggatccTTATTAC 'TCAGCGCTCAGCGGGCG-3' (BamHI site in lower case), respectively. The pET-11a vector (Novagen, Madison, WI) and the amplified DNA fragment containing oANG were digested with NdeI and BamHI and ligated to generate pET-11a-oANG. The encoded protein comprises 453 amino acids residues $(49.2 \mathrm{kDa})$, including the mature angiotensinogen $\left(\mathrm{D}^{25}-\mathrm{E}^{476}\right)$ of oANG [GenBank: BAA04470] [22] and an N-terminal M extension (derived from the initiation codon).

To produce an oANG expression plasmid with the protein under the control of the tac promoter, a pTACMAT-Tag vector (Sigma-Aldrich, St. Louis, MO) was modified by adding a new restriction enzyme site to the multiple cloning site. The $o A N G$ gene was amplified by PCR from pET-11a-oANG. The sequences of the forward and reverse primers were $5^{\prime}$-GGGGTCTAGAcatatgGAC CGCGTATACATCCACCCCTTC-3' (NdeI site in lower case) and 5'-GGGGAAGCTTctcgagCTCAGCGCTCAG CGGGC-3' (XhoI site in lower case), respectively. The amplified fragment and the pTAC vector were digested with NdeI and XhoI. The DNA fragment containing oANG was sub-cloned into the NdeI and XhoI sites of the pTAC vector to produce pTAC-oANG-His. The encoded protein comprises 461 amino acids residues $(50.3 \mathrm{kDa})$, including the mature angiotensinogen $\left(\mathrm{D}^{25}-\mathrm{E}^{476}\right)$ [22] 
as well as an $\mathrm{N}$-terminal $\mathrm{M}$ extension (derived from the initiation codon) and a C-terminal extension (LEHHHHHH).

\section{Expression of recombinant oANG in E. coli}

The pET-11a-oANG plasmid was used to transform six different E. coli host strains: BL21(DE3), Rosetta 2(DE3), Tuner(DE3), HMS174(DE3) (Novagen), SHuffle T7 Express Competent E. coli (SHB), and SHuffle T7 Competent E. coli (SHK) (New England Biolabs, Herts, UK). Ten randomly selected colonies were suspended in $0.05 \mathrm{~mL}$ of $\mathrm{LB}$ medium (Nacalai, Kyoto, Japan), and $0.02 \mathrm{~mL}$ of the suspensions were added to $2 \mathrm{~mL}$ of LB medium supplemented with either $50 \mu \mathrm{g} / \mathrm{mL}$ ampicillin [all host strains except for Rosetta 2(DE3)] or $50 \mu \mathrm{g} / \mathrm{mL}$ ampicillin and $25 \mu \mathrm{g} / \mathrm{mL}$ chloramphenicol [Rosetta 2(DE3)]. After the transformed cells were grown at $37{ }^{\circ} \mathrm{C}$ to mid-log phase $\left(\mathrm{OD}_{600}\right.$ approximately 0.6$)$, IPTG was added to the culture medium and protein expression was induced for $3 \mathrm{~h}$. IPTG concentrations and expression temperatures were varied in an attempt to improve the solubility of oANG. Cells were collected by centrifugation $(2,200 \times g, 10 \mathrm{~min}$, $\left.4{ }^{\circ} \mathrm{C}\right)$, resuspended in phosphate-buffered saline $(10 \mathrm{mM}$ $\mathrm{Na}_{2} \mathrm{HPO}_{4}, 1.8 \mathrm{mM} \mathrm{KH} \mathrm{PO}_{4}, 140 \mathrm{mM} \mathrm{NaCl}$, and $2.7 \mathrm{mM}$ $\mathrm{KCl}, \mathrm{pH} \mathrm{7.3),} \mathrm{and} \mathrm{disrupted} \mathrm{by} \mathrm{sonication.} \mathrm{The} \mathrm{soluble}$ and insoluble fractions were separated by centrifugation $\left(13,200 \times g, 15 \mathrm{~min}, 4{ }^{\circ} \mathrm{C}\right)$. All samples were analyzed by SDS-PAGE in $12 \%$ gels using either CBB staining or western blotting with rabbit anti-oANG polyclonal anti-serum (1:10,000 dilution) as a primary antibody [8]. In the western blot, the antigen-antibody complex was tagged using an anti-rabbit secondary antibody conjugated with a horseradish peroxidase and was detected by a chromogenic reaction using hydrogen peroxide and 3,3' -diaminobenzidine.

To examine the effect of the promoter, BL21(DE3) cells and BL21 cells were transformed with pET-11a-oANG and pTAC-oANG-His, respectively. Ten randomly selected colonies of each transformant were cultured in $2 \mathrm{~mL}$ of $\mathrm{LB}$ medium at $37^{\circ} \mathrm{C}$, and recombinant oANG expression was induced at $37{ }^{\circ} \mathrm{C}$ by the addition of $0.1 \mathrm{mM}$ IPTG for $3 \mathrm{~h}$. The harvested cells were suspended in $1 \mathrm{~mL}$ of Buffer A (20 mM Tris- $\mathrm{HCl}, 0.3 \mathrm{M} \mathrm{KCl}$, and $1 \mathrm{mM} \mathrm{MgCl}$, $\mathrm{pH}$ 7.6). The $\mathrm{OD}_{600}$ value of $E$. coli cells transformed with pET-11aoANG (containing a T7 promoter) was 0.81 , whereas that of cells transformed with pTAC-oANG-His (containing a tac promoter) was 0.79 . After disrupting the $E$. coli cells by sonication, the soluble and insoluble fractions were prepared for western blotting.

\section{Expression of recombinant oANG in E. coli}

E. coli BL21 cells were transformed with the pTACoANG-His plasmid. Ten randomly selected colonies were suspended and cultured in $2 \mathrm{~mL}$ of LB medium supplemented with $50 \mu \mathrm{g} / \mathrm{mL}$ ampicillin. After the transformed cells were grown at $37{ }^{\circ} \mathrm{C}$ to mid-log phase $\left(\mathrm{OD}_{600}\right.$ approximately 0.6), a culture aliquot was inoculated into $0.5 \mathrm{~L}$ of Overnight Express Instant TB medium (Novagen) [19] supplemented with $50 \mu \mathrm{g} / \mathrm{mL}$ ampicillin, $1 \%$ glycerol, and $0.01 \%$ Antifoam SI (Wako, Osaka, Japan). The cells were grown for $16 \mathrm{~h}$ at $30{ }^{\circ} \mathrm{C}$ using a novel culture system, aerated at 1 volume of air per unit volume of medium per min, and agitated at $600 \mathrm{rpm}$ with a magnetic stirrer bar ( $\phi 8 \mathrm{~mm}$, length $60 \mathrm{~mm}$ ) in a 2-L glass bottle. Cells were collected by centrifugation $\left(10,000 \times g, 10 \mathrm{~min}, 4{ }^{\circ} \mathrm{C}\right) \mathrm{using}$ a high-speed refrigerated centrifuge (Model 6000; Kubota, Japan). The cell pellets were stored at $-80{ }^{\circ} \mathrm{C}$ until use. About 2 days were required for this $E$. coli-based expression of oANG.

\section{Purification of recombinant oANG expressed in $E$. coli (oANG Ecoli $_{\text {) }}$}

Approximately $8 \mathrm{~g}$ of $E$. coli cells were suspended in $100 \mathrm{~mL}$ of Buffer A. After the addition of $3 \mu \mathrm{L}$ of 30 $\mathrm{KU} / \mu \mathrm{L}$ rLysozyme (Novagen) and $3 \mu \mathrm{L}$ of $25 \mathrm{U} / \mu \mathrm{L}$ Benzonase (Novagen), the cell suspension was incubated on ice for $30 \mathrm{~min}$ with gentle stirring. The cells were disrupted by sonication using an ultrasonic homogenizer (Microson XL2000; MISONIX). The cell lysate was centrifuged at $14,000 \times g$ for $30 \mathrm{~min}$ at $4{ }^{\circ} \mathrm{C}$, and the resulting supernatant was centrifuged again at $20,000 \times g$ for $15 \mathrm{~min}$ at $4{ }^{\circ} \mathrm{C}$. The clear supernatant was loaded onto a 1-mL Ni-NTA Superflow Cartridge column (Qiagen, Venlo, The Netherlands) equilibrated with Buffer A on an ÄKTAprime plus (GE Healthcare, Buckinghamshire, England). After washing with $0.01 \mathrm{M}$ imidazole in Buffer $\mathrm{A}$, proteins were eluted with a step-wise gradient $(0.01 \mathrm{M}-0.2 \mathrm{M})$ of imidazole in Buffer A. The Ni-NTA bound fractions were pooled, diluted 1:10 with $20 \mathrm{mM}$ Tris- $\mathrm{HCl}(\mathrm{pH} 8.0)$, and loaded onto a HiTrapQ HP column (GE Healthcare) equilibrated with the same buffer. Proteins were eluted with a linear gradient $(0.02 \mathrm{M}-0.4 \mathrm{M})$ of $\mathrm{KCl}$ in the same buffer. Bound fractions were pooled, concentrated using a Vivaspin Turbo 15 with a molecular cut-off of 10,000 (Sartorius, Goettingen, Germany), and subjected to gel filtration on a HiLoad 16/ 60 Superdex 200 pg column (GE Healthcare) equilibrated with $2 \mathrm{mM}$ 2-[4-(2-hydroxyethyl)-1-piperazinyl] ethanesulfonic acid (HEPES) and $0.2 \mathrm{M} \mathrm{KCl}(\mathrm{pH} \mathrm{8.0)}$. The oANGcontaining fractions were pooled and concentrated to $5.0 \mathrm{mg} / \mathrm{mL}$ using a Vivaspin Turbo 15 . The molar concentration of oANG was determined using the molecular extinction coefficient at $280 \mathrm{~nm}\left(39,165 \mathrm{M}^{-1} \mathrm{~cm}^{-1}\right)$, which was calculated according to the formula provided by Kuramitsu et al. [23].

\section{Preparation of recombinant oANG expressed in $\mathrm{CHO}$ cells (oANG ${ }_{\mathrm{CHO}}$ )}

Recombinant oANG was expressed in $\mathrm{CHO}$ cells and purified as described previously [8, 24]. About 30 days 
were required for the $\mathrm{CHO}$ cell-based expression of oANG. Approximately $0.8 \mathrm{~L}$ of serum-free culture medium was collected. Ammonium sulfate was added to the cleared culture medium to $70 \%$ saturation. After removing most of the supernatant, the precipitate was collected by centrifugation $\left(10,000 \times g, 10 \mathrm{~min}, 4^{\circ} \mathrm{C}\right)$. The precipitate was dissolved in $20 \mathrm{mM}$ sodium acetate $(\mathrm{pH} 5.0)$ and dialyzed against the same buffer. The dialysate was centrifuged at $10,000 \times g$ for $10 \mathrm{~min}$ at $4{ }^{\circ} \mathrm{C}$ to remove the insoluble material. The clear supernatant was loaded onto a HiTrap SP FF column (GE Healthcare) equilibrated with $20 \mathrm{mM}$ sodium acetate ( $\mathrm{pH}$ 5.0). oANG was eluted with a linear gradient of $\mathrm{NaCl}(0-1.0 \mathrm{M})$ in the same buffer. The bound fractions were pooled, concentrated using a Vivaspin Turbo 15, and subjected to gel filtration on a HiLoad 16/60 Superdex 200 pg column (GE Healthcare) equilibrated with $2 \mathrm{mM}$ HEPES and $0.2 \mathrm{M} \mathrm{KCl}(\mathrm{pH} 8.0)$. The oANG-containing fractions were pooled and concentrated to $3.0 \mathrm{mg} / \mathrm{mL}$ using a Vivaspin Turbo 15 . The above molecular extinction coefficient at $280 \mathrm{~nm}$ was used to estimate the molar concentration of oANG.

\section{Preparation of recombinant human renin}

Recombinant human prorenin was expressed in $\mathrm{CHO}$ cells and purified as described previously [5]. Approximately $1 \mathrm{~L}$ of serum-free culture medium was collected. Proteins in the cleared medium were precipitated with ammonium sulfate at $75 \%$ saturation. The precipitate was dissolved in $20 \mathrm{mM}$ acetate (pH 5.0) and dialyzed against the same buffer. Human prorenin was purified on a Resource $S$ column (GE Healthcare) with a linear gradient of $\mathrm{NaCl}(0-1.0 \mathrm{M})$ in $20 \mathrm{mM}$ acetate ( $\mathrm{pH}$ 5.0). Immediately after purification, fractions containing human prorenin were mixed with one-tenth volume of $0.1 \mathrm{M}$ Tris $(\mathrm{pH} \mathrm{8)}$ to neutralize the $\mathrm{pH}$. The protein concentration of human prorenin was determined using a molecular extinction coefficient at $280 \mathrm{~nm}$ of $47,705 \mathrm{M}^{-1} \mathrm{~cm}^{-1}$, which was calculated with the ProtParam tool [25], and the final concentration of human prorenin was $2.4 \mu \mathrm{M}$. Human prorenin was treated with trypsin to prepare human renin, as described previously [26].

\section{Protein assay}

Total protein concentration was measured as described by Bradford [27] using bovine serum albumin as a standard.

\section{Angiotensinogen assay}

The concentration of recombinant oANG was determined as described previously [8]. Recombinant oANG was incubated with excess human renin at $37^{\circ} \mathrm{C}$ for 30 and $45 \mathrm{~min}$ in $5 \mathrm{mM}$ sodium phosphate buffer $(\mathrm{pH} 7.2)$ containing $5 \mathrm{mM}$ diisopropyl fluorophosphates (DFP), $5 \mathrm{mM}$ EDTA, $100 \mathrm{mM} \mathrm{NaCl}$, and $0.1 \%(w / v)$ heat-denatured bovine serum albumin (fraction $\mathrm{V}$ ). The amount of AI generated was measured in triplicate by AI-ELISA [28]. The plateau amount of AI generated was represented as the concentration of recombinant oANG.

\section{Size-exclusion gel filtration analysis}

Purified oANG was subjected to gel filtration on a Superdex 200 10/300 GL column (GE Healthcare) equilibrated with $2 \mathrm{mM}$ HEPES and $0.20 \mathrm{M} \mathrm{KCl}(\mathrm{pH} 8.0)$ at a flow rate of $0.3 \mathrm{~mL} / \mathrm{min}$. The column was calibrated using the Gel Filtration Standard (Bio-Rad Laboratories, Hercules, CA). The calibration curve is represented by the equation $\mathrm{K}_{\mathrm{av}}=1.9754-0.3211\left(\log _{10} \mathrm{Mw}\right)$, where $\mathrm{K}_{\mathrm{av}}$ is the gel-phase distribution coefficient and $\mathrm{Mw}$ is the molecular weight of the protein.

\section{DLS analysis}

The DLS experiments were performed at $25{ }^{\circ} \mathrm{C}$ with a Zetasizer Nano-ZS (Malvern, Worcestershire, UK). Recombinant oANG preparations were diluted to a final concentration of $0.5 \mathrm{mg} / \mathrm{mL}$ with $20 \mathrm{mM}$ sodium phosphate (pH 7.4), and the oANG $\mathrm{Ecoli}_{\text {and }} \mathrm{oANG} \mathrm{CHO}_{\mathrm{CHO}}$ preparations contained 20 and $33 \mathrm{mM} \mathrm{KCl}$, respectively. Prior to the measurements, the samples were filtered (Ultrafree-MC, $0.22 \mu \mathrm{m}$, Millipore). The polydispersity, hydrodynamic radius, and empirically estimated molecular mass were calculated using the Zetasizer software provided by the manufacturer. The hydrodynamic radius was reported as the mean \pm standard deviation. The viscosity and refractive index values of the solvent used were $0.9056 \mathrm{cP}$ and 1.331, respectively, as calculated by the software.

\section{CD spectroscopic analysis}

CD spectra were recorded at $25{ }^{\circ} \mathrm{C}$ on a J-820 spectropolarimeter (Jasco International, Tokyo, Japan) equipped with a Peltier thermoregulation system using 1-mm thick quartz cells (S11-UV-10; GL Sciences). Recombinant oANG preparations were diluted to a final concentration of $0.5 \mathrm{mg} / \mathrm{mL}$ with $20 \mathrm{mM}$ sodium phosphate (pH 7.4), and the oANG $\mathrm{Ecoli}_{\text {and }}$ aANG $\mathrm{AHO}_{\mathrm{CHO}}$ preparations contained 20 and $33 \mathrm{mM} \mathrm{KCl}$, respectively. Prior to the measurements, the samples were filtered (Ultrafree-MC, $0.22 \mu \mathrm{m}$, Millipore). CD spectra between 190 and $260 \mathrm{~nm}$ were measured with a scanning speed of $50 \mathrm{~nm} / \mathrm{min}$ and a data pitch of $0.2 \mathrm{~nm}$. Spectra from eight scans were averaged. The contribution of buffer was subtracted from each spectrum. Mean residue ellipticity values were calculated assuming that the number of residues in $\mathrm{oANG}_{\mathrm{Ecoli}}$ and oANG $_{\mathrm{CHO}}$ was 461 and 452, respectively. The experimental data in the $200 \mathrm{~nm}-240 \mathrm{~nm}$ range were analyzed by the K2D3 web server [29] to estimate the secondary structure content. 


\section{DSF analysis}

DSF experiments were performed as described previously [11]. Recombinant oANG preparations were diluted in $200 \mathrm{mM}$ HEPES and $0.15 \mathrm{M} \mathrm{KCl}(\mathrm{pH} 7.5)$ to a final concentration of $20 \mu \mathrm{M}$. The fluorescent dye SYPRO Orange (Life Technologies, Carlsbad, CA) was diluted to $10 \times$ (from a $5000 \times$ stock). Recombinant oANG $(20 \mu \mathrm{M})$ and SYPRO Orange $(10 \times)$ were mixed in a 1:1 ratio. The mixture was aliquoted into a 96-well PCR plate and sealed with optical quality sealing film (Applied Biosystems, Foster City, CA). Thermal unfolding was carried out using a StepOnePlus real-time PCR instrument (Applied Biosystems) by heating from 25 to $95{ }^{\circ} \mathrm{C}$ at a rate of $1{ }^{\circ} \mathrm{C}$ per min. Fluorescence intensity was measured every $1{ }^{\circ} \mathrm{C}$ using a ROX filter at excitation and emission wavelengths of 490 and $600 \mathrm{~nm}-630 \mathrm{~nm}$, respectively. Fluorescence intensities in relative fluorescence units were plotted as a function of temperature. To estimate the $T_{\mathrm{m}}$, the Boltzmann equation was used to fit the fluorescence data using GraphPad Prism 5.0 software (GraphPad Software, La Jolla, CA) and the calculation templates downloaded from ftp://ftp.sgc.ox.ac.uk/pub/biophysics/ [11]. The $T_{\mathrm{m}}$ values were reported as the mean \pm standard deviation. Student's $t$-test was used to statistically analyze the results.

\section{Kinetic analysis}

Various concentrations $(0-0.4 \mu \mathrm{M})$ of recombinant oANG were incubated with human renin $(25 \mathrm{pM})$ at $37^{\circ} \mathrm{C}$ for $30 \mathrm{~min}$ in $5 \mathrm{mM}$ sodium phosphate buffer ( $\mathrm{pH} 7.2$ ) containing $8 \mathrm{mM}$ DFP, $8 \mathrm{mM}$ EDTA, $100 \mathrm{mM} \mathrm{NaCl}$, and $0.1 \%(\mathrm{w} / \mathrm{v})$ heat-denatured bovine serum albumin (fraction V). The rate of AI generation was determined by AI-ELISA [28]. The $K_{\mathrm{m}}$ and maximum velocity $\left(V_{\max }\right)$ were estimated by Hanes-Woolf plot using GraphPad Prism 5.0 software.

\section{Availability of data and material}

The datasets supporting the conclusions of this article are included within the article and its additional file.

\section{Additional file}

Additional file 1: Purification of recombinant OANG using Ni-affinity column chromatography. (PDF 64 kb)

\footnotetext{
Abbreviations

Al: angiotensin I; ANG: angiotensinogen; CBB: Coomassie Brilliant Blue; CD: circular dichroism; CHO: Chinese hamster ovary; DFP: diisopropyl fluorophosphates; DLS: dynamic light scattering; DSF: differential scanning fluorimetry; ELISA: enzyme-linked immunosorbent assay; HEPES: 2-[4-(2hydroxyethyl)-1-piperazinyl]ethanesulfonic acid; IPTG: isopropyl-beta-Dthiogalactoside; $k_{\text {cat }}$ : catalytic turnover; $k_{\text {cat }} / K_{m}$ : catalytic efficiency; $K_{\mathrm{m}}$ : Michaelis constant; OANG: ovine ANG; OANG $\mathrm{CHO}_{\mathrm{HO}}$ : ovine angiotensinogen expressed in $\mathrm{CHO}$ cells; OANGEcoli: ovine angiotensinogen expressed in E. coli; PRC: plasma renin concentration; SDS-PAGE: SDS-polyacrylamide gel
}

electrophoresis; serpin: serine protease inhibitor; SHB: SHuffle T7 Express Competent E. coli; SHK: SHuffle T7 Competent E. coli; $T_{\mathrm{m}}$ : melting temperature.

\section{Competing interests}

The authors declare that they have no competing interests.

\section{Authors' contributions}

SY designed the study, analyzed the data, and wrote the paper. NS performed the work and analyzed the data. ABI demonstrated the efficacy of a tac promoter and performed the preliminary protein characterization demonstrating that recombinant oANG is produced in an active form in E. coli. EA, Al, TYa, and $\mathrm{AH}$ prepared the protein and performed the characterization. $\mathrm{KI}$ and TT established our laboratory protocol for DSF. SI led the DLS experiments and analyzed the data. SO, TYO, and KN helped design the oANG expression procedure and guided the work by $\mathrm{ABI}$, who made the breakthrough in the protein production of oANG. KBB and AHMNN led the renin activity measurement using oANG. TN and FS continuously provided scientific and technical comments on this study. AE conceived the study, participated in its design and coordination, and helped draft the manuscript. All authors edited the manuscript and approved the final manuscript.

\section{Acknowledgements}

We thank Dr. Frank H. Niesen for providing the calculation template for DSF and Professor Makoto Kiso for his helpful comments. We also thank Ms. Keico Nakahara for technical support with protein expression and purification. This work was supported in part by a grant from Mr. Kiyomi Yoshizaki, by grants from Gifu University (KASSEIKA KEIHI) and the United Graduate School of Agricultural Science, Gifu University (WAKATE KASSEIKA KEIHI), and by the JSPS KAKENHI (Grant Nos. 24658092 and 15 K01707).

\section{Author details \\ 'United Graduate School of Agricultural Science, Gifu University, 1-1 Yanagido, Gifu 501-1193, Japan. ${ }^{2}$ Graduate School of Applied Biological Sciences, Gifu University, 1-1 Yanagido, Gifu 501-1193, Japan. ${ }^{3}$ Faculty of Engineering, Gifu University, 1-1 Yanagido, Gifu 501-1193, Japan. ${ }^{4}$ Faculty of Applied Biological Sciences, Gifu University, 1-1 Yanagido, Gifu 501-1193, Japan. ${ }^{5}$ Department of Biochemistry and Molecular Biology, University of Dhaka, Dhaka-1000, Bangladesh.}

Received: 24 November 2015 Accepted: 30 March 2016 Published online: 07 April 2016

\section{References}

1. Campbell DJ. The renin-angiotensin and the kallikrein-kinin systems. Int J Biochem Cell Biol. 2003;35:784-91.

2. Tanimoto K, Sugiyama F, Goto Y, Ishida J, Takimoto E, Yagami K, Fukamizu A, Murakami K. Angiotensinogen-deficient mice with hypotension. J Biol Chem. 1994:269:31334-7.

3. Yanai K, Saito T, Kakinuma Y, Kon Y, Hirota K, Taniguchi-Yanai K, Nishijo N, Shigematsu $Y$, Horiguchi $H$, Kasuya $Y$. Renin-dependent cardiovascular functions and renin-independent blood-brain barrier functions revealed by renin-deficient mice. J Biol Chem. 2000;275:5-8.

4. Skinner SL, Dunn JR, Mazzetti J, Campbell DJ, Fidge NH. Purification, properties and kinetics of sheep and human renin substrates. Aust J Exp Biol Med Sci. 1975:53:77-88

5. Nasir UM, Takahashi K, Nagai T, Nakagawa T, Suzuki F, Nakamura Y. Two peaks in $\mathrm{pH}$ dependence of renin-angiotensinogen reaction. Biosci Biotechnol Biochem. 1998;62:338-40.

6. Campbell DJ, Nussberger J, Stowasser M, Danser AH, Morganti A, Frandsen E, Menard J.Activity assays and immunoassays for plasma renin and prorenin: information provided and precautions necessary for accurate measurement. Clin Chem. 2009;55:867-77.

7. Fernley RT, John M, Niall HD, Coghlan JP. Purification and characterization of ovine angiotensinogen. Eur J Biochem. 1986;154:597-601.

8. Nagase M, Suzuki F, Sawai Y, Orihashi T, Inui Y, Nakagawa T, Nakamura Y. Purification and some properties of recombinant sheep angiotensinogen expressed in Chinese hamster ovary cells. Biomedical Research-Tokyo. 1997;18: 439-43.

9. Terpe K. Overview of bacterial expression systems for heterologous protein production: from molecular and biochemical fundamentals to commercial systems. Appl Microbiol Biotechnol. 2006;72:211-22. 
10. Ebihara A, Kondou T, Mizuno S, Nakagawa T, Nasir UM, Inui Y, Fukamizu A, Suzuki F, Nakamura Y, Murakami K. Molecular properties of recombinant ovine angiotensinogen. Biomedical Research-Tokyo. 2000;21:247-54.

11. Niesen $F H$, Berglund $H$, Vedadi $M$. The use of differential scanning fluorimetry to detect ligand interactions that promote protein stability. Nat Protoc. 2007;2:2212-21.

12. Nakagawa T, Nishiuchi K, Akaki J, Iwata H, Satou R, Suzuki F, Nakamura Y. Efficient production of recombinant human (pro)renin utilizing a decahistidine tag attached at the C-terminus. Biosci Biotechnol Biochem. 2007;71:256-60.

13. Doolittle RF. Angiotensinogen is related to the antitrypsin-antithrombinovalbumin family. Science. 1983;222:417-9.

14. Bird PI, Pak SC, Worrall DM, Bottomley SP. Production of recombinant serpins in Escherichia coli. Methods. 2004;32:169-76.

15. Kunapuli SP, Prasad GL, Kumar A. Expression of human angiotensinogen cDNA in Escherichia coli. J Biol Chem. 1987;262:7672-5.

16. Zhou A, Carrell RW, Murphy MP, Wei Z, Yan Y, Stanley PL, Stein PE, Broughton Pipkin F, Read RJ. A redox switch in angiotensinogen modulates angiotensin release. Nature. 2010:468:108-11.

17. Ikeda-Boku A, Ohno S, Hibino Y, Yokogawa T, Hayashi N, Nishikawa K. A simple system for expression of proteins containing 3-azidotyrosine at a pre-determined site in Escherichia coli. J Biochem. 2013;153:317-26.

18. Li Z, Carstensen B, Rinas U. Smart sustainable bottle (SSB) system for E. coli based recombinant protein production. Microb Cell Factories. 2014;13:153.

19. Grabski A, Mehler M, Drott D. The overnight express autoinduction system: high-density cell growth and protein expression while you sleep. Nat Methods. 2005;2:233-5.

20. Anfinsen CB. Principles that govern the folding of protein chains. Science. 1973;181:223-30.

21. Jaffe SR, Strutton B, Levarski Z, Pandhal J, Wright PC. Escherichia coli as a glycoprotein production host: recent developments and challenges. Curr Opin Biotechnol. 2014;30:205-10.

22. Nagase M, Suzuki F, Fukamizu A, Takeda N, Takeuchi K, Murakami K, Nakamura Y. Sequencing and expression of sheep angiotensinogen CDNA. Biosci Biotechnol Biochem. 1994;58:1884-5.

23. Kuramitsu S, Hiromi K, Hayashi H, Morino Y, Kagamiyama H. Pre-steady-state kinetics of Escherichia coli aspartate aminotransferase catalyzed reactions and thermodynamic aspects of its substrate specificity. Biochemistry. 1990;29:5469-76.

24. Ebihara A, Nasir UM, Yoshida S, Kondou T, Nakagawa T, Fukamizu A, Suzuki F, Nakamura Y, Murakami K. Sialic acid residue of ovine angiotensinogen does not affect the reactivity to human renin. Biomedical Research-Tokyo. 2000:21:105-9.

25. Gasteiger E, Hoogland C, Gattiker A, Duvaud S, Wilkins M, Appel R, Bairoch A. Protein Identification and Analysis Tools on the ExPASy Server. In: Walker J, editor. The proteomics protocols handbook. Totowa: Humana Press; 2005. p. 571-607.

26. Suzuki F, Nakagawa T, Kakidachi H, Murakami K, Inagami T, Nakamura Y. The dominant role of the prosegment of prorenin in determining the rate of activation by acid or trypsin: studies with molecular chimeras. Biochem Biophys Res Commun. 2000;267:577-80.

27. Bradford MM. A rapid and sensitive method for the quantitation of microgram quantities of protein utilizing the principle of protein-dye binding. Anal Biochem. 1976;72:248-54.

28. Suzuki F, Yamashita S, Takahashi A, Ito M, Miyazaki S, Nagata Y, Nakamura Y. Highly sensitive microplate-ELISA for angiotensin I using 3,3'5,5'tetramethylbenzidine. Clin Exp Hyper. 1990;A12:83-95.

29. Louis-Jeune C, Andrade-Navarro MA, Perez-Iratxeta C. Prediction of protein secondary structure from circular dichroism using theoretically derived spectra. Proteins. 2012;80:374-81.

\section{Submit your next manuscript to BioMed Central and we will help you at every step:}

- We accept pre-submission inquiries

- Our selector tool helps you to find the most relevant journal

- We provide round the clock customer support

- Convenient online submission

- Thorough peer review

- Inclusion in PubMed and all major indexing services

- Maximum visibility for your research

Submit your manuscript at www.biomedcentral.com/submit
Biomed Central 